\title{
Synthesis and behavior of bulk iron nitride soft magnets via high-pressure spark plasma sintering
}

\author{
Todd C. Monson ${ }^{1, a)}$ (D, Baolong Zheng ${ }^{2}$, Robert E. Delaney ${ }^{1}$, Charles J. Pearce ${ }^{1}$, Yizhang Zhou ${ }^{2}$, \\ Stanley Atcitty ${ }^{1}$, Enrique Lavernia ${ }^{2}$ \\ ${ }^{1}$ Sandia National Laboratories, Albuquerque, NM 87185, USA \\ ${ }^{2}$ University of California, Irvine, CA 92697, USA \\ a) Address all correspondence to this author. e-mail: tmonson@sandia.gov \\ Received: 25 May 2021; accepted: 2 September 2021; published online: 1 November 2021
}

In this study, dense bulk iron nitrides $\left(\mathrm{Fe}_{x} \mathrm{~N}\right)$ were synthesized for the first time ever using spark plasma sintering (SPS) of $\mathrm{Fe}_{x} \mathrm{~N}$ powders. The $\mathrm{Fe}_{4} \mathrm{~N}$ phase of iron nitride in particular has significant potential to serve as a new soft magnetic material in both transformer and inductor cores and electrical machines. The density of SPSed $\mathrm{Fe}_{x} \mathrm{~N}$ increased with SPS temperature and pressure. The microstructure of the consolidated bulk $\mathrm{Fe}_{x} \mathrm{~N}$ was characterized with X-ray diffraction (XRD), scanning electron microscopy (SEM), transmission electron microscopy (TEM), and superconducting quantum interference device (SQUID) magnetometry. XRD revealed a primary phase of $\mathrm{Fe}_{4} \mathrm{~N}$ with secondary phases of $\mathrm{Fe}_{3} \mathrm{~N}$ and metallic iron. Finite element analysis (FEA) was also applied to investigate and explain localized heating and temperature distribution during SPS. The effects of processing on interface bonding formation and phase evolution were investigated and discussed in detail to provide insight into fundamental phenomena and microstructural evolution in SPSed $\mathrm{Fe}_{x} \mathrm{~N}$.

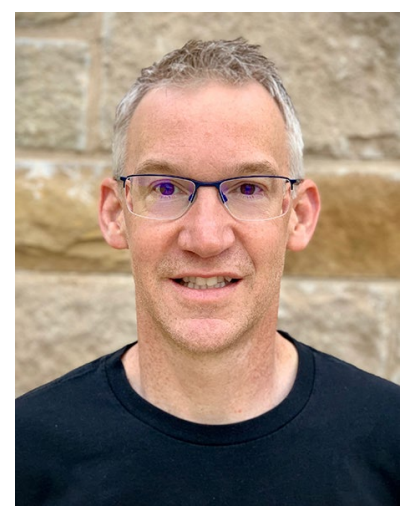

Todd C. Monson is a Principal Member of the Technical Staff at Sandia National Laboratories, where he has worked since 2005. Todd earned both a Ph.D. (2012) and M.A. (2001) in physics from the University of Texas at Austin. Prior to coming to Sandia, Todd served as a physicist in the U.S. Air Force for over seven years, working at both the Air Force Research Laboratory's Munitions Directorate and serving as an assistant professor of physics at the U.S. Air Force Academy. Todd received his commission in the U.S. Air Force after graduating with a B.S. in physics from the U.S. Naval Academy in May of 1997. Todd's research interests include the synthesis and characterization of ferromagnetic and ferroelectric materials in both bulk and composite form. He seeks greater understanding of ferroic behavior at all length scales from ranging from Ångstrom to macroscale. In the field of magnetics, Todd's research has primarily focused on the synthesis of new soft magnetic materials to enable increased power density and energy efficiency in inductors, transformers, and electrical machines.

\section{Introduction}

New, high-saturation magnetization $\left(M_{\mathrm{s}}\right)$ and low-loss soft magnetic materials will be vital for the next generation of power conversion electronics and electrical machines [1]. Since iron nitrides $\left(\mathrm{Fe}_{x} \mathrm{~N}, x=2-4\right)$ are comprised entirely of low-cost abundant elements and many phases of the iron nitride system offer the promise of better magnetic properties, this class of materials beckons further investigation $[2,3]$.
$\mathrm{Fe}_{x} \mathrm{~N}$ has been studied for decades due to both its ability to improve surface hardness and wear resistance of components [4] and impressive magnetic properties [5-9]. According to experimental results $[2,10,11]$ from thin films and theoretical calculations [2], several phases of iron nitride would have magnetic moments well in excess of current state of the art soft magnetic materials. Therefore, $\mathrm{Fe}_{x} \mathrm{~N}$ would be ideally suited for use in many applications, such as both transformer and inductor 
cores and in electrical machines. To date, $\mathrm{Fe}_{x} \mathrm{~N}$ has primarily been fabricated as thin films, powder, or inclusions in other materials $[11,12]$. Bulk $\mathrm{Fe}_{x} \mathrm{~N}$ was rarely fabricated because a relatively high sintering temperature is required using conventional powder sintering processes. $\mathrm{Fe}_{x} \mathrm{~N}$ is semi-metallic and generally thermally metastable. The decomposition of $\mathrm{Fe}_{x} \mathrm{~N}$ into $\mathrm{Fe}$ and $\mathrm{N}_{2}$ upon heating to $863 \mathrm{~K}$ was previously noted $[13,14]$. Therefore, dense bulk $\mathrm{Fe}_{x} \mathrm{~N}$ is challenging to synthesize.

Spark plasma sintering (SPS), a low-temperature fieldassisted sintering technique (FAST), has been studied as an attractive consolidation technique for powder. SPS uses pulsed current and pressure to achieve lower sintering temperatures, fast heating rates, and brief consolidation cycles [15-17]. In view of the above facts, we have investigated the synthesis and magnetic behavior of dense bulk $\mathrm{Fe}_{x} \mathrm{~N}$ from $\mathrm{Fe}_{x} \mathrm{~N}$ powders using SPS, which enables the direct consolidation and shaping of $\mathrm{Fe}_{x} \mathrm{~N}$ transformer and inductor cores from raw starting materials in a matter of minutes, without the decomposition of $\mathrm{Fe}_{x} \mathrm{~N}$ that would occur using conventional sintering techniques [13]. Microstructural evaluation of consolidated samples using SPS

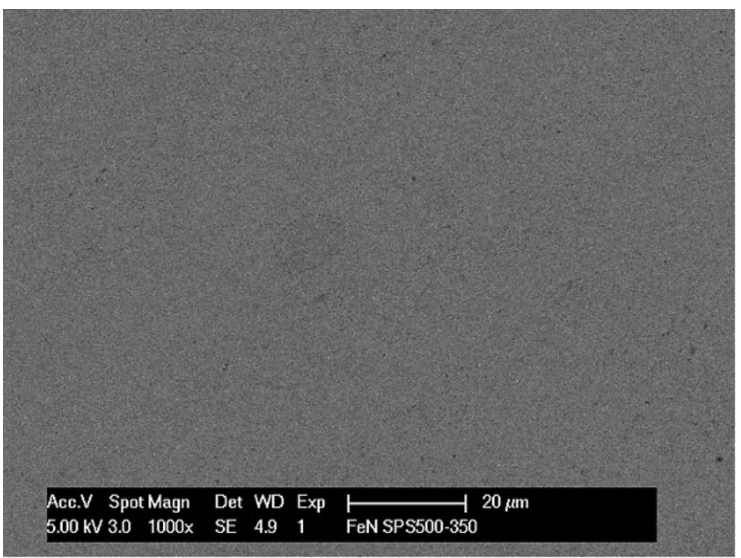

(a)

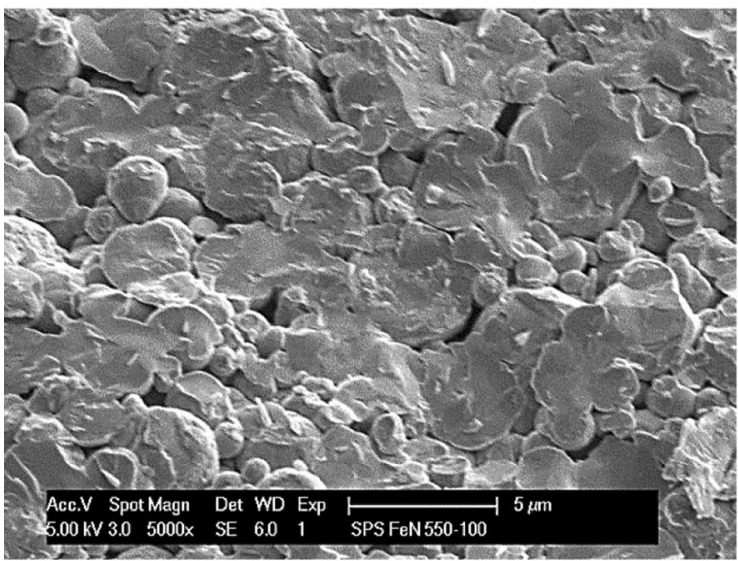

(c) was then evaluated using X-ray diffraction (XRD), scanning electron microscopy (SEM), and transmission electron microscopy (TEM). Their magnetic properties were also measured and evaluated using magnetometry. COMSOL FEA software was also applied to investigate and explain the localized heating and temperature distribution during SPS of $\mathrm{Fe}_{x} \mathrm{~N}$ powder. The underlying mechanisms of interface bonding and formation, thermal stability, and phase transition are also discussed in an effort to elucidate fundamental phenomena in SPSed $\mathrm{Fe}_{x} \mathrm{~N}$.

\section{Results}

\section{Microstructure of SPSed $\mathrm{Fe}_{x} \mathrm{~N}$}

The typical microstructure corresponding to SPSed $\mathrm{Fe}_{x} \mathrm{~N}$ (at $823 \mathrm{~K}$ and $350 \mathrm{MPa}$ ) is shown in Fig. 1a. At low magnification in the polished sections, uniform contrast is observed without secondary phases being evident. Almost full densification (up to $99 \%$ of the theoretical density of $\mathrm{Fe}_{4} \mathrm{~N}$ ), without visible porosity, was achieved in the SPSed $\mathrm{Fe}_{x} \mathrm{~N}$ samples. The interfaces between particles are not evident, suggesting that the

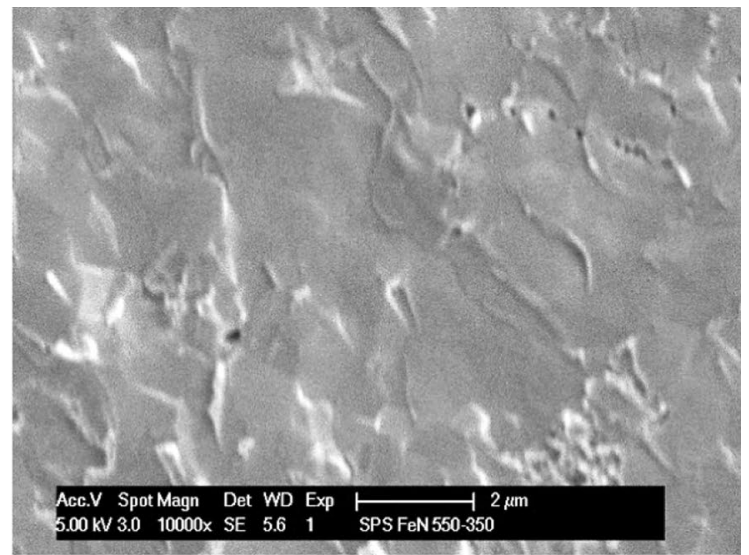

(b)

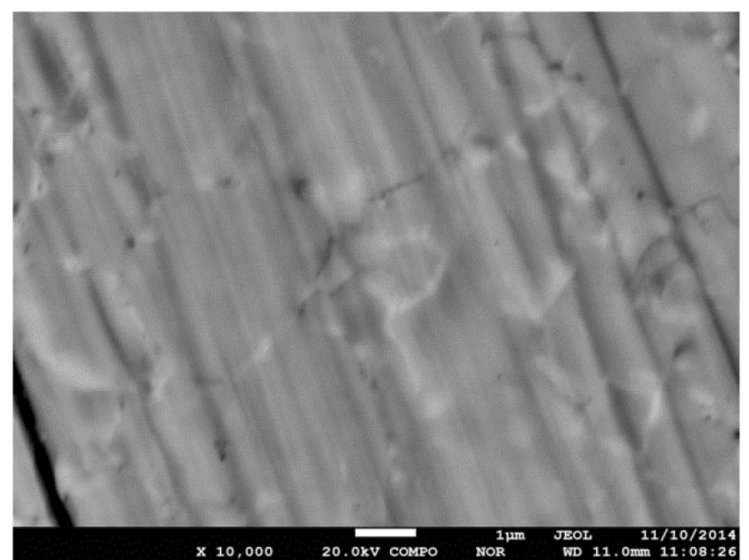

(d)

Figure 1: SEM micrograph and fractograph of SPSed $\mathrm{Fe}_{x} \mathrm{~N}$ samples with different pressures (a), (b) $823 \mathrm{~K}, 350 \mathrm{MPa}$, (c) $823 \mathrm{~K}, 100 \mathrm{MPa}$, and (d) the surface of a toroid sintered at $823 \mathrm{~K}, 100 \mathrm{MPa}$. 
interface bonding between particles was enhanced compared with samples SPSed at a lower pressure of $100 \mathrm{MPa}$. A small volume fraction (approximately 0.8 vol\% measured from SEM imaging) of pores was observed in the microstructure of samples SPSed at $823 \mathrm{~K}$ and $350 \mathrm{MPa}$, as shown in Fig. $1 \mathrm{~b}$. It was also observed that the density of SPSed $\mathrm{Fe}_{x} \mathrm{~N}$ samples clearly increased with SPS pressure. The fracture surface corresponding to this SPSed $\mathrm{Fe}_{x} \mathrm{~N}$ material, shown in Fig. $1 \mathrm{~b}$ and $c$, reveals transparticle fracture features, which suggests strong particle-particle bonding formation and effective load transfer. It is interesting to observe that there is a variation of contrast around the particles' boundaries, as shown in Fig. 1d. A variation in composition was observed in SPSed $\mathrm{Fe}_{x} \mathrm{~N}$ between the particles' boundaries and centers. Traces collected using wavelength dispersive spectroscopy (WDS) showed that the stoichiometry in the center of each grain is close to $\mathrm{Fe}_{4} \mathrm{~N}$ (81.3 at.\% $\mathrm{Fe}$ ), while the iron content at the grain boundaries (GBs) is about 3 atomic percent richer $(84.2$ at.\% $\mathrm{Fe}$ ). The slightly higher concentration of $\mathrm{Fe}$ at the grain boundaries in the WDS data is consistent with the lighter grain boundaries seen in the backscattered electron (BSE) SEM image (refer to Figure S1). Table S1 in the supplementary information summarizes the WDS data from the surface of a sintered toroid.

Figure 2 shows the XRD patterns corresponding to $\mathrm{Fe}_{x} \mathrm{~N}$ SPSed at $773 \mathrm{~K}, 798 \mathrm{~K}$, and $823 \mathrm{~K}$ with pressures ranging from 200 to $500 \mathrm{MPa}$. XRD analysis indicates that SPSed $\mathrm{Fe}_{x} \mathrm{~N}$ contains primarily two crystalline phases, $\mathrm{Fe}_{4} \mathrm{~N}$ and $\mathrm{Fe}_{3} \mathrm{~N}$. One $\mathrm{Fe}_{x} \mathrm{~N}$ sample sintered at $823 \mathrm{~K}$ and $350 \mathrm{MPa}$ shows a peak around a $2 \Theta$ value of $26^{\circ}$, likely due to decomposition of $\mathrm{Fe}_{x} \mathrm{~N}$ into iron metal. This decomposition may be occurring due to localized higher temperatures during sintering and the increased pressure used during the consolidation of this sample. Other SPSed samples did not exhibit the same peak.

The microstructure and interface characteristics of SPSed $\mathrm{Fe}_{x} \mathrm{~N}$ were further investigated by TEM analysis. A typical bright field TEM micrograph of the microstructure of SPSed $\mathrm{Fe}_{x} \mathrm{~N}$ at $823 \mathrm{~K}$ and $200 \mathrm{MPa}$ is shown in Fig. 3. The $\mathrm{Fe}_{x} \mathrm{~N}$ particles once again appear well consolidated with very little porosity. The voids between particles have almost entirely disappeared. Twins were also observed in some SPSed $\mathrm{Fe}_{x} \mathrm{~N}$ grains. Twin boundaries (TBs) can greatly improve mechanical properties [18], such as strength and ductility. The grain size of SPSed $\mathrm{Fe}_{x} \mathrm{~N}$ ranged from $200 \mathrm{~nm}$ to $1 \mu \mathrm{m}$.

\section{Properties of SPSed $\mathrm{Fe}_{\boldsymbol{x}} \mathrm{N}$}

To investigate the thermal stability of $\mathrm{Fe}_{x} \mathrm{~N}$, differential scanning calorimetry (DSC) was used, as shown in Fig. 4. During heating, there is an exothermic event beginning at $873 \mathrm{~K}$, corresponding to the decomposition of $\mathrm{Fe}_{x} \mathrm{~N}$. Therefore, sintering temperatures must be kept below this temperature to avoid simultaneous decomposition during consolidation.

The densities of $\mathrm{Fe}_{x} \mathrm{~N}$ consolidated using different sintering temperatures and pressures are shown in Fig. 5. As expected, density increases with increasing SPS temperature and pressure. The highest density of $7.08 \mathrm{~g} / \mathrm{cm}^{3}$ was achieved in a sample SPSed at $773 \mathrm{~K}$ and $500 \mathrm{MPa}$. This equates to $99 \%$ of the theoretical density of $\mathrm{Fe}_{4} \mathrm{~N}\left(7.179 \mathrm{~g} / \mathrm{cm}^{3}\right)$.

The density of $\mathrm{Fe}_{x} \mathrm{~N}$ samples produced with MM powder was also measured. $\mathrm{AR} \mathrm{Fe}_{x} \mathrm{~N}$ powder was mechanical milled using a high-energy ball miller (SPEX 8000D) for $4 \mathrm{~h}$ in argon

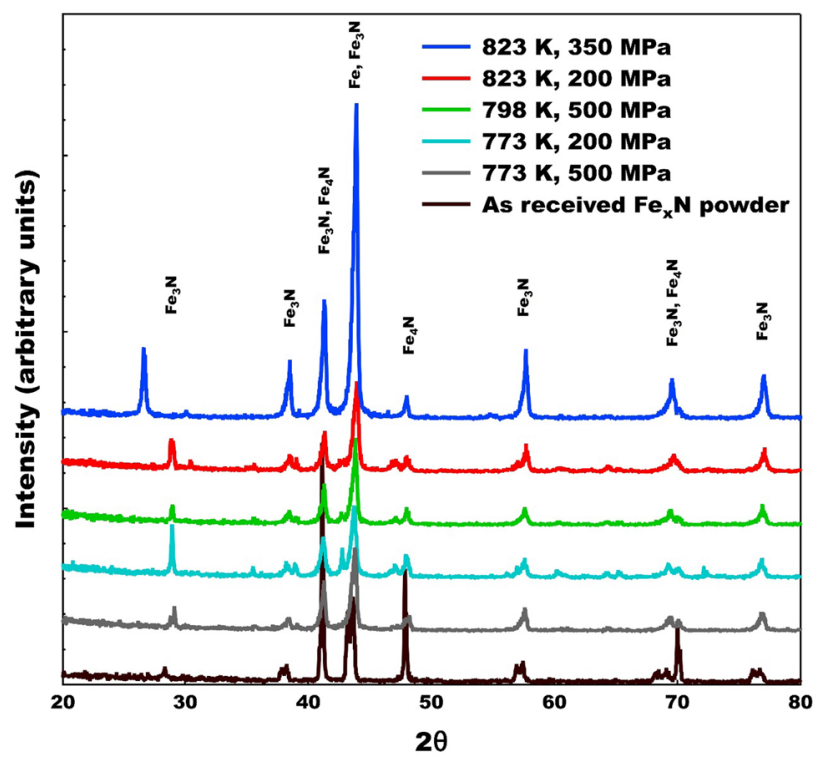

Figure 2: XRD patterns of bulk $\mathrm{Fe}_{x} \mathrm{~N}$ samples SPSed with different conditions. 


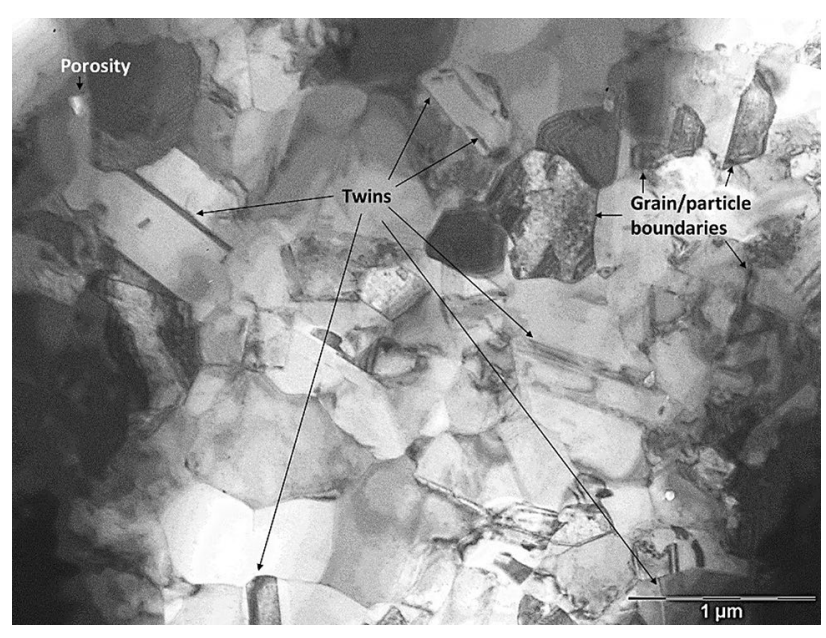

Figure 3: TEM bright field micrograph of SPSed $\mathrm{Fe}_{x} \mathrm{~N}$ at $823 \mathrm{~K}$ and $200 \mathrm{MPa}$.

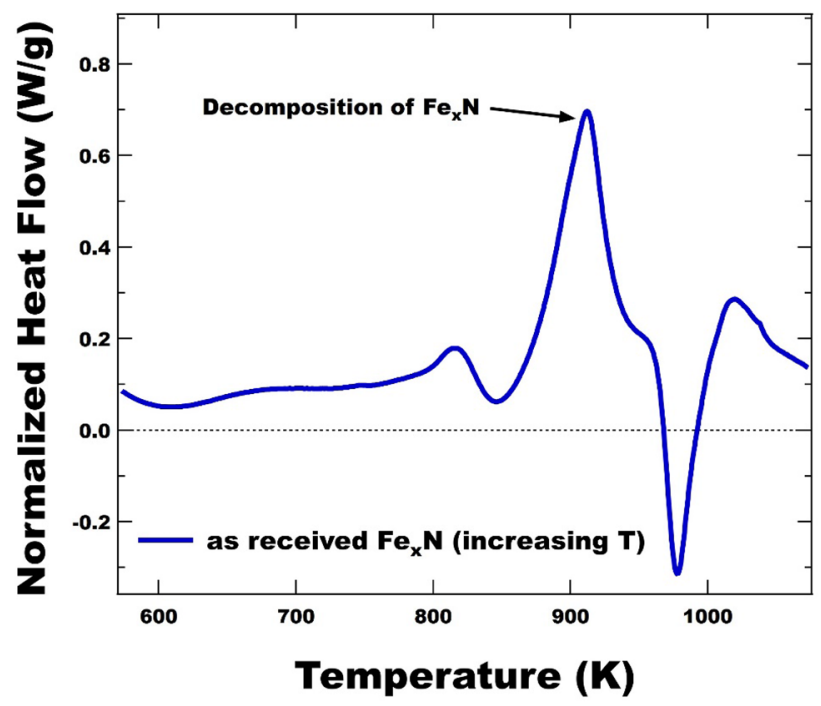

Figure 4: DSC pattern of bulk Fe $\mathrm{N}_{x}$ sample SPSed at $823 \mathrm{~K}$ and $200 \mathrm{MPa}$. Endothermic reactions are represented by positive heat flow (y-axis).

atmosphere at room temperature. The ball to $\mathrm{AR} \mathrm{Fe}_{x} \mathrm{~N}$ powder weight ratio used in our experiments was 5:1. The density of samples produced using milled $\mathrm{Fe}_{x} \mathrm{~N}$ powder is significantly higher than those produced with $\mathrm{AR} \mathrm{Fe}_{x} \mathrm{~N}$ powder under the same SPS processing conditions. Increased density is most likely due to higher packing density and greater diffusion during sintering as a result of finer particle sizes [19]. Additionally, there is a higher degree of variation in the density of samples produced with AR powder when compared with those produced with milled $\mathrm{Fe}_{x} \mathrm{~N}$ powder.

Magnetic properties of the SPSed $\mathrm{Fe}_{x} \mathrm{~N}$ samples were also investigated. Figure 6 shows the magnetic hysteresis ( $M$ vs. $H$ ) curves of the SPSed $\mathrm{Fe}_{x} \mathrm{~N}$ with as-received FexN powder. The saturation magnetization $\left(M_{\mathrm{s}}\right)$, coercivity $\left(H_{\mathrm{c}}\right)$, and relative permeability $\left(\mu_{\mathrm{r}}\right)$ of the samples vary only slightly with SPS temperature and pressure. $\mathrm{Fe}_{x} \mathrm{~N}$ sintered at $823 \mathrm{~K}$ and $200 \mathrm{MPa}$ achieved a $M_{\mathrm{s}}$ of $188 \mathrm{~A} \cdot \mathrm{m}^{2} / \mathrm{kg}$, a $H_{\mathrm{c}}$ of $9.20 \times 10^{2} \mathrm{~A} / \mathrm{m}$, and a $\mu_{\mathrm{r}}$ of 6.84. The measured value of $M_{\mathrm{s}}$ is less than the theoretical value of $209 \mathrm{~A} \cdot \mathrm{m}^{2} / \mathrm{kg}$ [3], which is primarily due to presence of the secondary $\mathrm{Fe}_{3} \mathrm{~N}$ phase. The soft magnetic properties of SPSed FexN could be further improved by improving phase purity of the raw materials, refining grain size of the raw materials, and optimizing SPS-processing conditions to persevere both phase purity and a fine grain size.

\section{Discussion}

Consolidation of nitrides generally requires both high temperatures and pressures. However, the relatively low thermal stability of $\mathrm{Fe}_{x} \mathrm{~N}$ (recall decomposition begins at $873 \mathrm{~K}$ ) limits the use of 


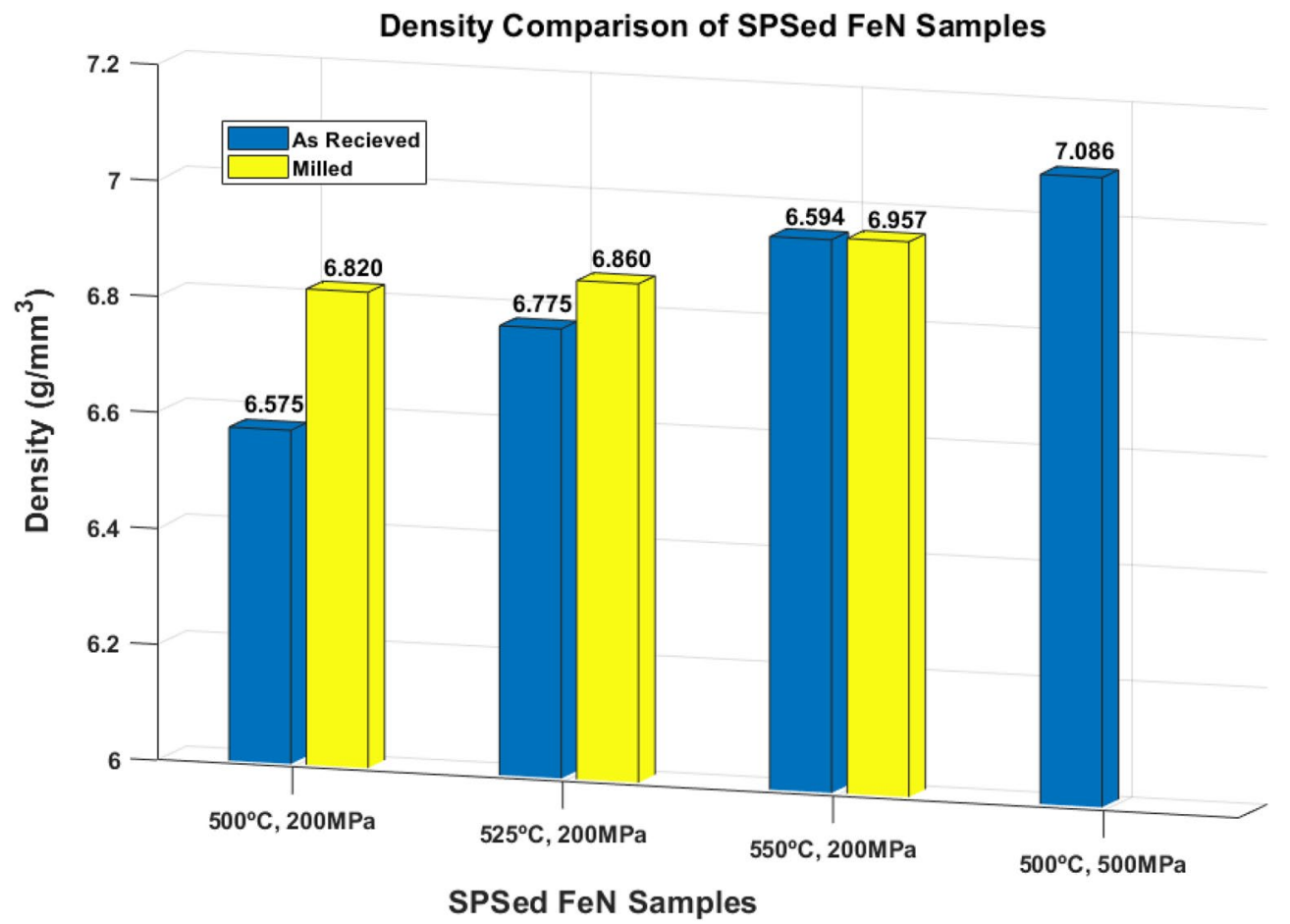

Figure 5: Density of SPSed $\mathrm{Fe}_{x} \mathrm{~N}$ samples with $\mathrm{AR}$ and milled $\mathrm{Fe}_{x} \mathrm{~N}$ powder. As a reference, the theoretical density of $\mathrm{Fe}_{4} \mathrm{~N}$ is $7.179 \mathrm{~g} / \mathrm{cm}^{3}$.

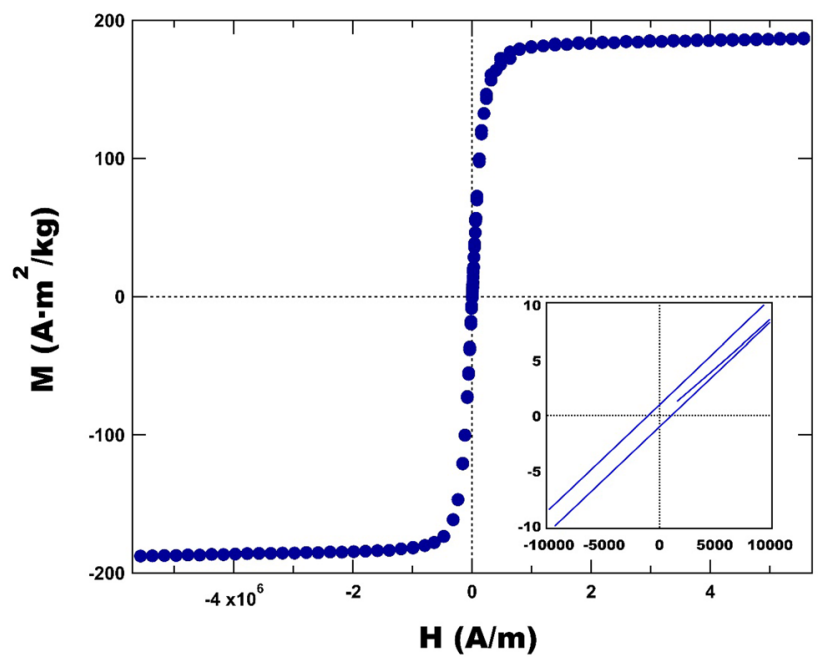

Figure 6: Field dependent magnetic response of SPS consolidated $\mathrm{Fe}_{x} \mathrm{~N}$.

higher temperature for consolidation. Therefore, SPS is the most suitable approach for consolidating dense, bulk $\mathrm{Fe}_{x} \mathrm{~N}$.

The SPS process represents a multiple-field problem in which the electric, thermal, and displacement (i.e., shrinkage) fields are coupled via a material response. This problem is strongly nonlinear since the fields interact and affect the properties of SPSed materials. The consolidation of $\mathrm{Fe}_{x} \mathrm{~N}$ with SPS is related to the deformation behavior of each particle, which also depends on internal defects (i.e., grain boundaries
(GBs), dislocations, twins, vacancies, etc.,), as well as the local pressure and temperature. In particular, spatial variations in the thermal and stress fields are likely conditions that can promote interface bonding and formation. During SPS, a pulsed current passes though both die and powder (according to its electrical conductivity), which will promote thermal energy and mass transfer. The thermal energy generated in the graphite die from Joule heating is transferred to the powder via conduction and limited radiation. The heat transfer 
in sintered particles can be expressed in the thermal energy equation as follows [20]: of a small contact area and a high local current density, as shown in Fig. 7, a FEA simulation of the early stage of sintering. Con-

$$
\frac{1}{r^{2}} \frac{\partial}{\partial r}\left(k r^{2} \frac{\partial T}{\partial r}\right)+\frac{1}{r^{2} \sin ^{2} \theta} \frac{\partial}{\partial \varphi}\left(k \frac{\partial T}{\partial \varphi}\right)+\frac{1}{r^{2} \sin \theta} \frac{\partial}{\partial \theta}\left(k \sin \theta \frac{\partial T}{\partial \theta}\right)+\dot{q}=\rho c_{p} \frac{\partial T}{\partial t}
$$

where $\rho$ is density, $c_{\mathrm{p}}$ is specific heat, and $q$ is energy rate generated per unit volume for conduction analysis with spherical coordinates $(r, \Phi, \theta)$. In the case of micron-sized particles, the internal temperature is equilibrated within several milliseconds. However, during SPS processing, the continuity of the electric field is disrupted by the presence of multiple interfaces. A local increase in temperature from electrical Joule heating can be calculated using Joule's law, as follows:

$$
T=I^{2} \cdot R \cdot t / m \cdot c_{\mathrm{p}}
$$

where $I$ is the electric current, $R$ is electrical resistance, $t$ is time, $m$ is mass, and $c_{\mathrm{p}}$ is the specific heat of the SPSed materials. Local increases in temperature will occur from the combination tact areas contain higher current and heat flux, and flat contact areas contain twice as much current/heat flux than in slanted contact areas. It has also been proposed that a spark discharge may occur at inter-particle regions [15], leading to localized partial melting and perhaps even to the formation of a metallic vapor [21] for some alloys as a result of elevated localized temperatures. Under the influence of the pressure, thermal, and electromagnetic fields, constricted geometries or "necks" are formed around the contact area between particles by localized heating and localized high stress, which can result in surface activation. These necks gradually develop and deformation progresses during sintering, resulting in densification. Meanwhile, grain growth or decomposition is possible at the contact

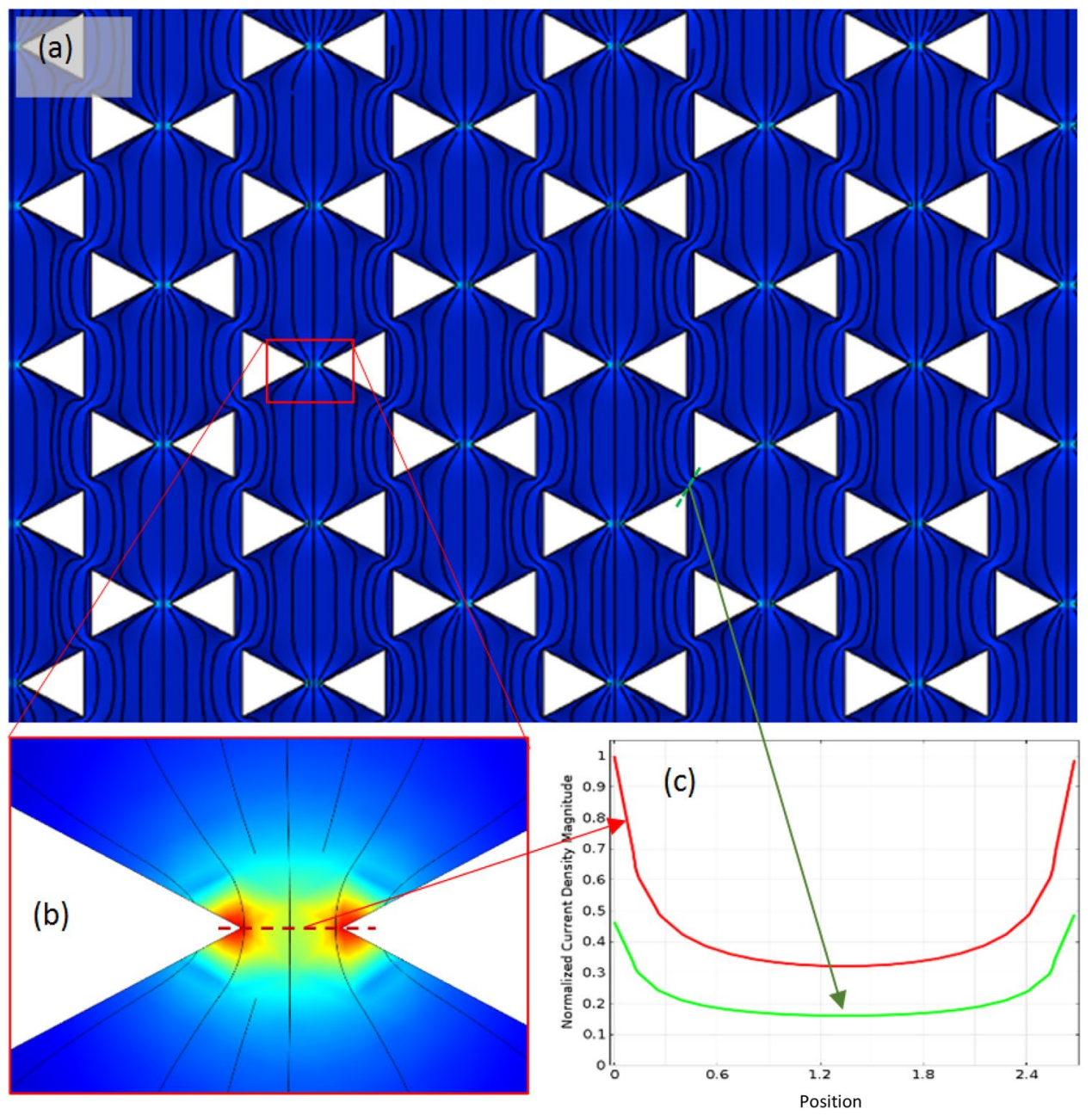

Figure 7: FEA simulation results of current/heat flux concentrations on the outer portions of the contact areas. 
area between particles due to the activation of localized higher temperature and stress $[22,23]$. As shown both in the WDS data discussed previously and in the BSE SEM image in Fig. 1d (see also Figure $\mathrm{S} 1$ ), $\mathrm{Fe}_{x} \mathrm{~N}$ partially decomposed at the particle boundary, resulting in a decreased amount of $\mathrm{N}$ because the localized temperature in the particle boundary was higher than the decomposition temperature of $\mathrm{Fe}_{x} \mathrm{~N}, 873 \mathrm{~K}$.

As many twins are present in SPSed $\mathrm{Fe}_{x} \mathrm{~N}$, as shown in Fig. 3, the strength and ductility of SPSed $\mathrm{Fe}_{x} \mathrm{~N}$ can be improved as it has been revealed that twin boundaries (TBs) can greatly improve the strength and ductility of brittle materials. Dislocation accumulation in TBs for brittle materials, such as carbides and nitrides [1], creates strength and ductility enhancement $[18,24]$. Thus, this represents a strategy by which $\mathrm{SPSed} \mathrm{Fe}_{x} \mathrm{~N}$ might gain some plasticity. The formation of twins can thermodynamically decrease the total interfacial energy, because the excess energy for coherent TBs is much smaller than that for conventional high-angle GBs. It was reported that twins prefer to nucleate at GBs to reduce the sum of the interfacial energies (including GBs and TBs) [18] by means of the twinning-induced orientation change.

The milled $\mathrm{Fe}_{x} \mathrm{~N}$ powders were found to exhibit a marked improvement in density after SPS processing relative to AR spherical $\mathrm{Fe}_{x} \mathrm{~N}$ powders. This can be attributed to the obvious differences in particle morphology and increase in surface area per unit volume. The $\mathrm{AR} \mathrm{Fe}_{x} \mathrm{~N}$ powders have a spherical shape with a relatively smooth surface whereas the milled powders have an irregular morphology and rough surface in addition to a smaller average size. Surface area per unit volume and curvature both increase with decreasing particle size, resulting in higher energy per unit volume, which enhances diffusion and thus sintering kinetics $[17,25]$. Neck growth during sintering, for example, increases with decreasing particle size. Another important influence of particle size on sintering is related to a temperature reduction with particle size, which can be expressed by [25]:

$$
T_{2}=\frac{1}{\frac{1}{T_{1}}-\frac{K M}{Q} \ln \frac{D_{2}}{D_{1}}}
$$

where $T_{1}$ and $T_{2}$ are the sintering temperatures for a change in particle size of $D_{1}$ and $D_{2}$, respectively, assuming the sintering time is constant. $M$ is a constant, $Q$ is the sintering activation energy, and $K$ is the Boltzmann's constant. If $D_{2}<D_{1}, T_{2}<T_{1}$, and a lower sintering temperature can be used.

It is anticipated that the soft magnetic properties of nanostructured $\mathrm{Fe}_{x} \mathrm{~N}$ materials can benefit from grain refinement [26]. Moreover, both a reduction in electrical conductivity and an increase in thermal conductivity are also requirements for the application of $\mathrm{Fe}_{x} \mathrm{~N}$ as soft magnetic materials. Both the electrical and thermal conductivity of a material are related to the scattering of electrons or photons [27]. The electrical resistivity increases as a result of electron scattering by imperfections, such as grain boundaries (GBs), impurities, dislocations and vacancies. On the other hand, thermal conductivity mainly depends on phonon scattering by GBs and the presence "insulating" phases (such as porosity). As a rule of thumb, decreasing the electrical conductivity while simultaneously increasing thermal conductivity is a challenge for most of materials. Thermal and electrical conductivity measurements of $\mathrm{Fe}_{4} \mathrm{~N}$ will be forthcoming in future work as improvements to phase purity in SPSed samples are realized.

Nanostructured $\mathrm{Fe}_{x} \mathrm{~N}$ powder can be formed through ball milling of as-received $\mathrm{Fe}_{x} \mathrm{~N}$ powder. Recall, GBs in crystal materials behave as obstacles for electron and thermal transmission. Nanocrystals have large surface-to-volume ratios, so the electrical conductivity of nanocrystalline materials is lower than that of the corresponding coarse-grained materials. In addition, it is known that the soft magnetic properties (increased $\mu$ and reduced $H_{c}$ ) can be further improved by reduction in grain size [28].

In addition to grain refinement into the nanocrystalline range and the accompanying high volume fraction of GBs induced by ball milling, nanostructures store a large excess of energy in nonequilibrium defects, such as dislocations, and vacancies, which constitute effective obstacles for electron transport, decreasing the electrical conductivity. Therefore, the electrical conductivity of bulk $\mathrm{Fe}_{x} \mathrm{~N}$ can be decreased by developing nanocrystalline structures and defects in $\mathrm{Fe}_{x} \mathrm{~N}$ using high-energy ball milling. We do have to consider that the grain refinement may also lead to a reduction in the thermal conductivity. However, the magnitude of change, from grain refinement, in electrical conductivity and the thermal conductivity of nanocrystalline $\mathrm{Fe}_{x} \mathrm{~N}$ may vary, and will require furthermore investigation. Once again, improvements in the final phase purity of sintered $\mathrm{Fe}_{4} \mathrm{~N}$ will be required before undertaking this study.

The thermal conductivity of SPSed $\mathrm{Fe}_{x} \mathrm{~N}$ can be enhanced by increasing the density of consolidated $\mathrm{Fe}_{x} \mathrm{~N}$ by through the use of high pressure (up to $500 \mathrm{MPa}$ ). The thermal conductivity of materials decreases with increasing porosity, since the presence of air or vacuum in the pores adds insulation. Even though bulk $\mathrm{Fe}_{x} \mathrm{~N}$ has been successfully fabricated with SPS, porosity was still found due to the high strength of $\mathrm{Fe}_{x} \mathrm{~N}$ and low sintering temperatures applied. The fraction of porosity in SPSed $\mathrm{Fe}_{x} \mathrm{~N}$ was decreased with increasing SPS temperature and pressure. Additionally, the density of samples with milled $\mathrm{Fe}_{x} \mathrm{~N}$ powder is significantly higher than those produced from as-received powder under the same SPS processing conditions.

The sintering temperature is limited by the decomposition temperature of $\mathrm{Fe}_{x} \mathrm{~N}(873 \mathrm{~K})$, so only higher pressures can be used to further decrease sample porosity. Therefore, high density nanostructured $\mathrm{Fe}_{x} \mathrm{~N}$ components can be developed using high-energy ball-milled $\mathrm{Fe}_{x} \mathrm{~N}$ powder and novel 
SPS double-die setups with SiC plungers. Dense, nanostructured $\mathrm{Fe}_{x} \mathrm{~N}$ will also have improved thermal conductivity as well as enhanced magnetic properties and mechanical properties. The magnitude of change in electrical conductivity and the thermal conductivity from reduction of porosity requires further investigation. Decreased porosity would also improve magnetic properties, increasing both magnetic saturation and permeability.

\section{Conclusion}

In this work, $\mathrm{AR}$ micron-sized $\mathrm{Fe}_{x} \mathrm{~N}$ powder was consolidated using SPS at temperatures of $773 \mathrm{~K}, 798 \mathrm{~K}$ and $823 \mathrm{~K}$, and pressures ranging from 100 to $500 \mathrm{MPa}$. Nearly fully dense bulk $\mathrm{Fe}_{x} \mathrm{~N}$ materials were SPSed at $825 \mathrm{~K}$ and $350 \mathrm{MPa}$. SPS with high pressure can be used to consolidate dense $\mathrm{Fe}_{x} \mathrm{~N}$ at lower temperatures to avoid decomposing of $\mathrm{Fe}_{x} \mathrm{~N}$. In addition, three toroids have been directly net shaped using SPS with $\mathrm{AR}$ and mechanical milled $\mathrm{Fe}_{x} \mathrm{~N}$ powder. The high heating efficiency and high pressure of SPS lead to nearly full densification of $\mathrm{Fe}_{x} \mathrm{~N}$ powder. SPSed $\mathrm{Fe}_{x} \mathrm{~N}$ shows a high-saturation magnetization of $188 \mathrm{~A} \cdot \mathrm{m}^{2} / \mathrm{kg}$. The theoretical value of 209 $\mathrm{A} \cdot \mathrm{m}^{2} / \mathrm{kg}$ for $\mathrm{Fe}_{4} \mathrm{~N}$ is within reach through improvements phase purity. Magnetic properties will be improved further through improvements not just in phase purity but also through grain size refinement, and decreased porosity. The sintering behavior and underlying mechanisms that govern $\mathrm{Fe}_{x} \mathrm{~N}$ consolidation during SPS were discussed in terms of the variation of density as well as the effects of twins in SPSed $\mathrm{Fe}_{x} \mathrm{~N}$, in an effort to understand the fundamental phenomena in bulk $\mathrm{Fe}_{x} \mathrm{~N}$ prepared by SPS processing.

\section{Methods}

The starting material used in this study was as-received (AR) commercial $\mathrm{Fe}_{x} \mathrm{~N}$ powder from Alfa Aesar. The $\mathrm{Fe}_{x} \mathrm{~N}$ powder exhibits a spherical morphology with particle size of smaller than $45 \mu \mathrm{m}$. Bulk $\mathrm{Fe}_{x} \mathrm{~N}$ samples were consolidated via SPS, using a SPS-825S DR. SINTER (SPS Syntex Inc., Japan) under vacuum conditions (lower than $1 \mathrm{~Pa}$ ). Generally, pressures up to $100 \mathrm{MPa}$ can be applied with a conventional graphite SPS die, as illustrated in Fig. 8a. In order to apply higher pressures to increase the density of SPSed $\mathrm{Fe}_{x} \mathrm{~N}$, a specially designed SPS double-die setup with SiC plungers, as illustrated in Fig. 8b, was utilized.

Figure 9 shows the SEM morphology of (a) AR FexN powder and (b) SPEX mechanical milled (MM) $\mathrm{Fe}_{x} \mathrm{~N}$ powder. The AR and $\mathrm{MM} \mathrm{Fe}_{x} \mathrm{~N}$ powder were loaded in an assembled die of graphite and SiC. SPS was performed at different temperatures and with a holding time of three minutes. Sintering pressures of 100 to $350 \mathrm{MPa}$ were used for producing disks with a diameter of $10 \mathrm{~mm}$ and thickness of $2 \mathrm{~mm}$, as shown in Fig. 9c, and $500 \mathrm{MPa}$ was applied when consolidating disks with a diameter of $5 \mathrm{~mm}$ and thickness of $2 \mathrm{~mm}$. Table 1 contains a list of SPSed disk samples and their processing parameters. The purpose of varying sintering temperature and pressure was to investigate their influence on the density, phase transformation, and magnetic behavior of sintered $\mathrm{Fe}_{x} \mathrm{~N}$. Three toroids were directly net shaped, eliminating the need for machining, using SPS (798 $\mathrm{K}$ and $100 \mathrm{MPa}$ ) with $\mathrm{AR}$ and milled $\mathrm{Fe}_{x} \mathrm{~N}$ powder as shown in Fig. 9d. In order to SPS toroidal shaped parts, die were designed according to the desired dimensions of the toroids. A drawing of the SPS graphite die is included in

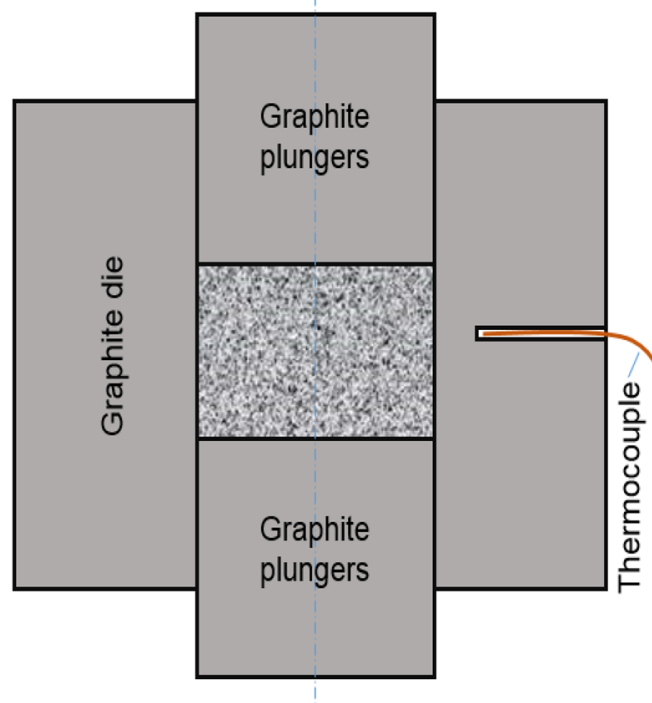

(a)

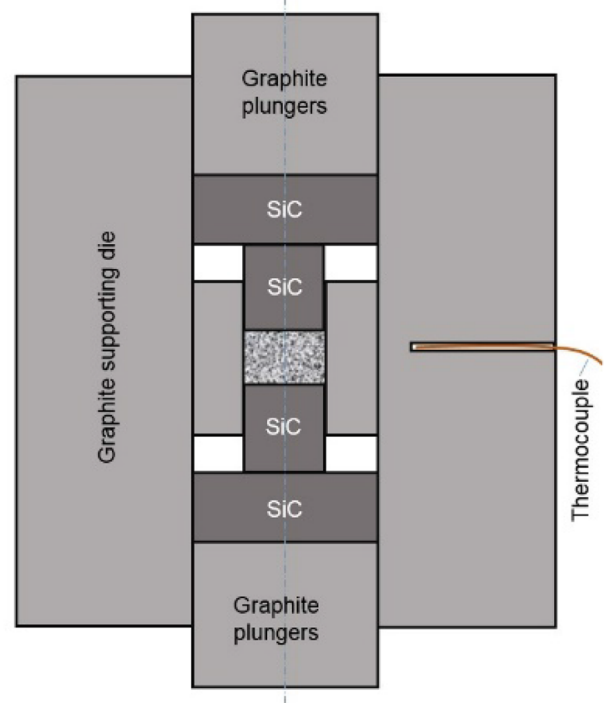

(b)

Figure 8: Schematic diagram of (a) a conventional graphite SPS die, and (b) a special SPS double-die with SiC plungers. 


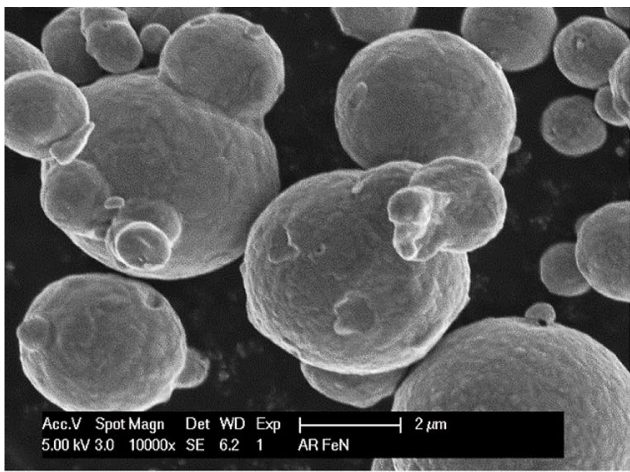

(a)

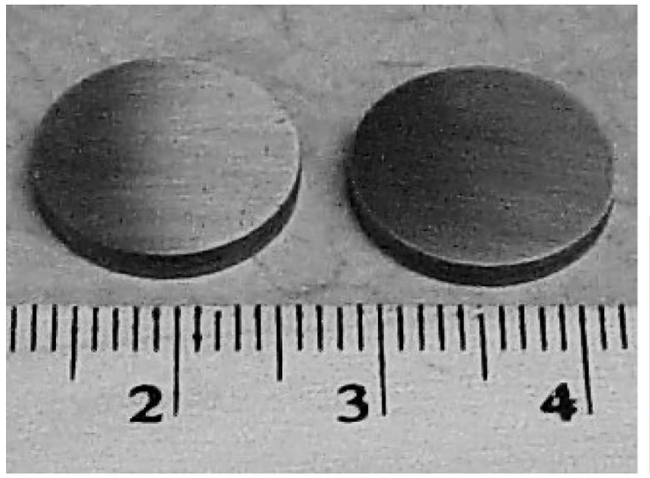

(c)

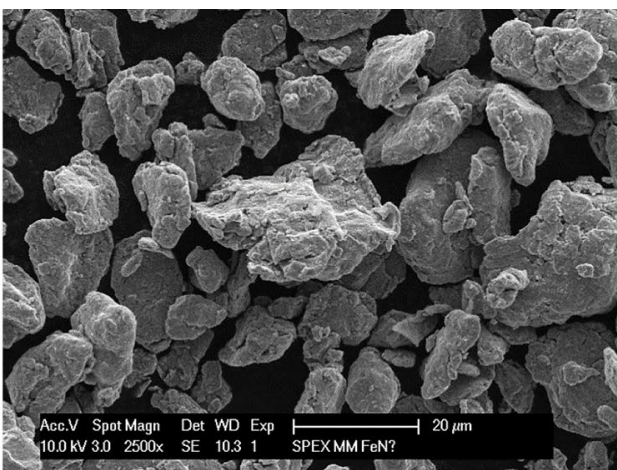

(b)

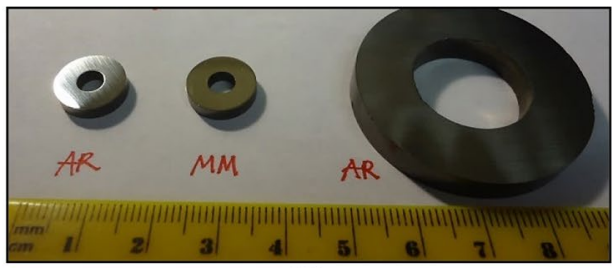

(d)

Figure 9: SEM morphology of (a) AR Fe $e_{x} N$ powder and (b) SPEX milled Fe $e_{x} N$ powder, and pictures of (c) SPSed Fe ${ }_{x} N$ disks and (d) SPSed net-shaped Fe ${ }_{x} N$ toroids.

TABLE 1: Process conditions for SPSing $\mathrm{Fe}_{x} \mathrm{~N}$ powder.

\begin{tabular}{lcccc}
\hline \hline Sample & Powder & $\begin{array}{c}\text { Temperature } \\
(\mathrm{K})\end{array}$ & $\begin{array}{c}\text { Pressure } \\
(\mathrm{MPa})\end{array}$ & $\begin{array}{c}\text { Hold time } \\
(\mathrm{min})\end{array}$ \\
\hline 1 & $\mathrm{AR} \mathrm{Fe}_{x} \mathrm{~N}$ powder & 773 & 100 & 3 \\
2 & & & 200 & \\
3 & & 400 & 500 \\
4 & & 200 \\
5 & 798 & 100 \\
6 & 823 & 200 \\
7 & & 350 \\
8 & & & \\
\hline
\end{tabular}

the supplementary information (Figure S2). High machining accuracy was required for the graphite dies, especially for the concentric inner and outside diameters of the dies and plungers. Iron nitride powder was added according to the toroid dimensions, filling the space between the outer die and inner mandrel. The sintered toroids are net-shaped, eliminating any need for machining.

The microstructure of SPSed $\mathrm{Fe}_{x} \mathrm{~N}$ was studied using SEM, energy dispersive X-ray spectroscopy (EDS), and TEM. Additional microstructure information was collected using wavelength dispersive spectroscopy (WDS). WDS analysis was performed on a JEOL JXA-8530F Electron Probe MicroAnalyzer, a Field Emission Microprobe. Beam conditions were a $20 \mathrm{keV}, 20 \mathrm{nA}$, spot beam. Nitrogen Ka was analyzed using an LDE2 crystal with Boron Nitride as the standard. Iron Ka was analyzed using an LIFL crystal with iron metal as the standard. Standards used were on the Taylor Metals Standard Block \#2, obtained from Charles M. Taylor.

Thin foils for TEM observations were prepared via mechanical grinding and polishing to a thickness of about $30 \mu \mathrm{m}$, followed by ion milling to a thickness of electron transparency using a Gatan precision ion polishing system (PIPS) 691 until perforation occurred. XRD using $\mathrm{Cu}$ Ka radiation was utilized for phase identification, and differential scanning calorimetry (DSC) was used for thermal stability studies. The magnetic behavior of the consolidated bulk $\mathrm{Fe}_{x} \mathrm{~N}$ materials were measured using a Quantum Design MPMS-7 superconducting quantum interference device (SQUID) magnetometer. The density of SPSed $\mathrm{Fe}_{x} \mathrm{~N}$ samples was measured using an analytical density determination based on the Archimedes principle.

Numerical simulation was also used to elucidate the effect that electrical field has on the formation of interfaces between $\mathrm{Fe}_{x} \mathrm{~N}$ particles during the SPS process. The governing physics equations are solved numerically using finite element analysis (FEA) as implemented with COMSOL (Palo Alto, CA). 


\section{Acknowledgments}

Sandia National Laboratories is a multi-mission laboratory managed and operated by National Technology and Engineering Solutions of Sandia, LLC., a wholly owned subsidiary of Honeywell International, Inc., for the U.S. Department of Energy's National Nuclear Security Administration under contract DE-NA-0003525. This paper describes objective technical results and analysis. Any subjective views or opinions that might be expressed in the paper do not necessarily represent the views of the U.S. Department of Energy or the United States Government. The authors acknowledge support for this work from Dr. Imre Gyuk and the Energy Storage Program in the Office of Electricity Delivery and Energy Reliability at the US Department of Energy. The authors would like to acknowledge Dick Grant at Sandia National Laboratories for his assistance in the collection of SEM imagery and Evan Schehrer, now at Montana State University, for his assistance with data analysis, and Dr. Alan Williamson at University of California, Davis for his help in the FEM simulation.

\section{Supplementary Information}

The online version contains supplementary material available at https://doi.org/10.1557/s43578-021-00379-z.

\section{Open Access}

This article is licensed under a Creative Commons Attribution 4.0 International License, which permits use, sharing, adaptation, distribution and reproduction in any medium or format, as long as you give appropriate credit to the original author(s) and the source, provide a link to the Creative Commons licence, and indicate if changes were made. The images or other third party material in this article are included in the article's Creative Commons licence, unless indicated otherwise in a credit line to the material. If material is not included in the article's Creative Commons licence and your intended use is not permitted by statutory regulation or exceeds the permitted use, you will need to obtain permission directly from the copyright holder. To view a copy of this licence, visit http://creativecommons.org/ licenses/by/4.0/.

\section{References}

1. Y. Li, Y.H. Zhao, W. Liu, Z.H. Zhang, R.G. Vogt, E.J. Lavernia, J.M. Schoenung, Philos. Mag. 90, 783-792 (2010)

2. S. Bhattacharyya, J. Phys. Chem. C 119, 1601-1622 (2015)
3. J.M.D. Coey, Magnetism and Magnetic Materials (Cambridge University Press, New York, 2010), p. 408

4. A. Fry, Stahl Eisen (in German) 43, 1271-1279 (1923)

5. K.H. Jack, Proc. R. Soc. A A208, 200-215 (1951)

6. T.K. Kim, M. Takahashi, Appl. Phys. Lett. 20, 492-494 (1972)

7. S. Okamoto, O. Kitakami, Y. Shimada, J. Appl. Phys. 85, 4952-4954 (1999)

8. A. Leineweber, H. Jacobs, W. Kockelmann, S. Hull, Physica B 276(278), 266 (2000)

9. A. Tayal, M. Gupta, A. Gupta, V. Ganesan, L. Behera, S. Singh, S. Basu, Surf. Coat. Technol. 275, 264-269 (2015)

10. Y. Takagi, K. Isami, I. Yamamoto, T. Nakagawa, T. Yokoyama, Phys. Rev. B 81, 035422 (2010)

11. Z.N. Kayani, S. Riaz, S. Naseem, Surf. Rev. Lett. 21, 1450013 (2014)

12. P. Prieto, F.J. Palomares, J.M. Gonzalez, R. Pérez-Casero, J.M. Sanz, Surf. Interface Anal. 38, 392-395 (2006)

13. S. Ito, S. Shinmura, T. Hosokoshi, K. Akashi, J. Jpn. Soc. Powder Metall. 43, 1415-1419 (1996)

14. H.A. Wriedt, N.A. Gokcen, R.H. Nafziger, Bull. Alloys Phase Diagr. 8, 355-377 (1987)

15. R. Orrù, R. Licheri, A.M. Locci, A. Cincotti, G. Cao, Mater. Sci. Eng. R. Rep. 63, 127-287 (2009)

16. S. Lee, H. Kato, T. Kubota, A. Makino, A. Inoue, Intermetallics 17, 218-221 (2009)

17. N. Zhou, T. Hu, J. Huang, J. Luo, Scr. Mater. 124, 160-163 (2016)

18. L. Lu, Y.F. Shen, X.H. Chen, L.H. Qian, K. Lu, Science 304, 422 (2004)

19. B. Zheng, D. Ashford, Y. Zhou, S.N. Mathaudhu, J.-P. Delplanque, E.J. Lavernia, Acta Mater. 61, 4414-4428 (2013)

20. F.P. Incropera, D.P. DeWitt, Fundamentals of Heat and Mass Transfer (Wiley, New York, 1996)

21. Z.A. Munir, U. Anselmi-Tamburini, M. Ohyanagi, J. Mater. Sci. 41, 763-777 (2006)

22. F.R.N. Nabarro, Scr. Mater. 39, 1681-1683 (1998)

23. A.J. Haslam, D. Moldovan, V. Yamakov, D. Wolf, S.R. Phillpot, H. Gleiter, Acta Mater. 51, 2097-2112 (2003)

24. K. Lu, Nat. Rev. Mater. 1, 16019 (2016)

25. R.M. German, Sintering Theory and Practice (Wiley, New York, 1996)

26. G. Herzer, Acta Mater. 61, 718-734 (2013)

27. Y. Lan, A.J. Minnich, G. Chen, Z. Ren, Adv. Funct. Mater. 20, 357-376 (2010)

28. M.E. McHenry, M.A. Willard, D.E. Laughlin, Prog. Mater Sci. 44, 291-433 (1999) 